\title{
MODIFIKASI DIAMETER INLET DAN PENGARUH KEKERASAN KARET TERHADAP HASIL LADA PADA MESIN PENGUPAS LADA SISTEM CRUSHER
}

\author{
Firlya Rosa ${ }^{1}$, Rodiawan, Elyas Kustiawan \\ Staff Pengajar Jurusan Teknik Mesin, Fakultas Teknik, Universitas Bangka Belitung \\ Sur-el: firlya@ubb.ac.id ${ }^{1}$
}

\begin{abstract}
ABSTRAK
Penelitian terdahulu didapatkan spesifikasi mesin terbaik pada kemiringan piringan sebesar $0,68^{\circ}$ dengan diameter inlet sebesar $30 \mathrm{~mm}$. Kapasitas input mesin yang didapat sebesar $1 \mathrm{~kg} / \mathrm{jam}$ dan kapasitas output mesin sebesar $0,64 \mathrm{~kg} / \mathrm{jam}$. Dari hasil evaluasi, untuk memperbesar kapasitas input perlu memperbesar diameter inlet dan menganalisa pengaruh kekerasan karet terhadap hasil pengelupasan lada. Metodologi penelitian yang dilakukan secara kualitatif hasil lada kering secara visualisasi maupun kuantitatif dengan menghitung waktu proses dan persentase lada terkelupas. Dari hasil memperbesar diameter inlet didapatkan kapasitas input menjadi $6 \mathrm{~kg} / \mathrm{jam}$ atau meningkat 5 kalinya dibandingkan kapasitas input penelitian terdahulu. Dengan kekerasan karet 60 shore A didapatkan persentase lada terkelupas sebesar 72,13\% dengan kapasitas output mesin sebesar 4,33 kg/jam. Untuk kekerasan karet sebesar 70 shore A didapatkan persentase lada terkelupas sebesar 73,03\% dengan kapasitas output mesin sebesar 4,38 kg/jam. Secara visualisasi, lada kering dengan kekerasan 60 shore A lebih putih dibandingkan lada kering kekerasan dengan kekerasan 70 shore A.
\end{abstract}

Kata kunci: lada, diameter inlet, kekerasan karet

\begin{abstract}
Based on previous research, specifications of machine have a slope of a dish of $0.68^{\circ}$ and inlet diameter of 30 $\mathrm{mm}$, produce $1 \mathrm{~kg} / \mathrm{hour}$ of input capacity and $0.64 \mathrm{~kg} / \mathrm{hour}$ of output capacity. From the evaluation results, to increase the input capacity it is necessary to increase the inlet diameter and analyze the effect of rubber hardness on the results of peeling pepper. The methodology of research is using qualifitative visualively and quantitatively by the measurement process and the percentage is peeled off. Modifiying the inlet diameter, input capacity increase to $6 \mathrm{~kg} / \mathrm{hour}$ or increasing 5 times compared to the input capacity of the previous research. For hardness of rubber 60 shore A, the percentage of pepper peeled was $72.13 \%$ with an engine output capacity of $4.33 \mathrm{~kg} / \mathrm{hour}$. For rubber hardness of 70 shore A, the percentage of pepper peeled was $73.03 \%$ with an engine output capacity of $4.38 \mathrm{~kg}$ / hour. Visually, dry pepper with a hardness of 60 shore A whiter than dry pepper hard with a hardness of 70 shore A.
\end{abstract}

Key words: pepper, inlet diameter, rubber hardness

\section{PENDAHULUAN}

[1] Meneliti mesin pengupas lada dengan menggunakan sistem crusher yang merupakan sistem penekanan yang dilakukan oleh 2 piringan yang saling bergesekan dengan benda kerja. Piringan terdiri dari piringan tetap dan piringan berputar di mana masing-masing piringan dilapisi dengan karet yang berdimensi diameter 380 dengan ketebalan 10 $\mathrm{mm}$ dengan bentuk piringan seperti pada gambar 1 dan gambar 2. Antara piringan tetap dan piringan berputar terdapat kemiringan.

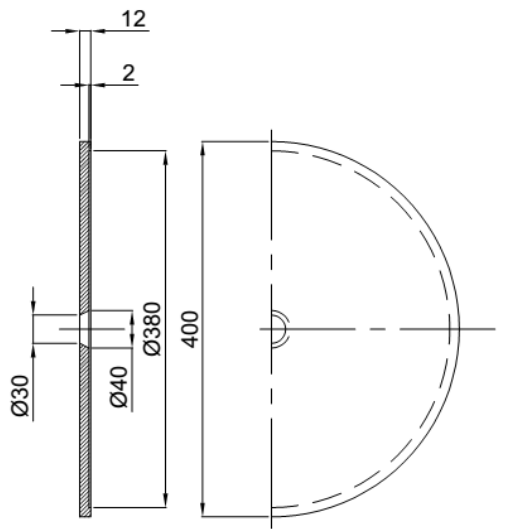

Gambar 1 Geomteri dan Dimensi Piringan Tetap 


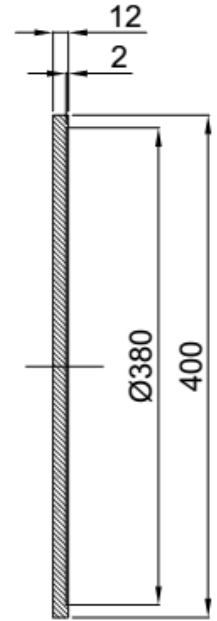

\section{Gambar 2 Geometri dan Dimesin Piringan Berputar}

Adapun alur kerja mesin pengupas lada adalah lada dimasukkan ke dalam inlet bersamaan dengan air yang mengalir. Melalui inlet, lada yang terbawa oleh air menuju piringan tetap. Piringan tetap berfungsi mengarahkan lada yang masuk melalui inlet. Dari piringan tetap, lada mengikuti alur-alur yang berada di piringan berputar dimana piringan berputar berfungsi untuk menggesek dan meggiring biji lada terhadap piringan tetap. Gesekan terjadi karena adanya kemiringan jarak antara piringan tetap dan piringan berputar sekaligus membawa lada menuju pinggiran piringan menuju tempat keluaran lada. Adapun bentuk mesin lada yang telah diteliti seperti pada gambar 3 .

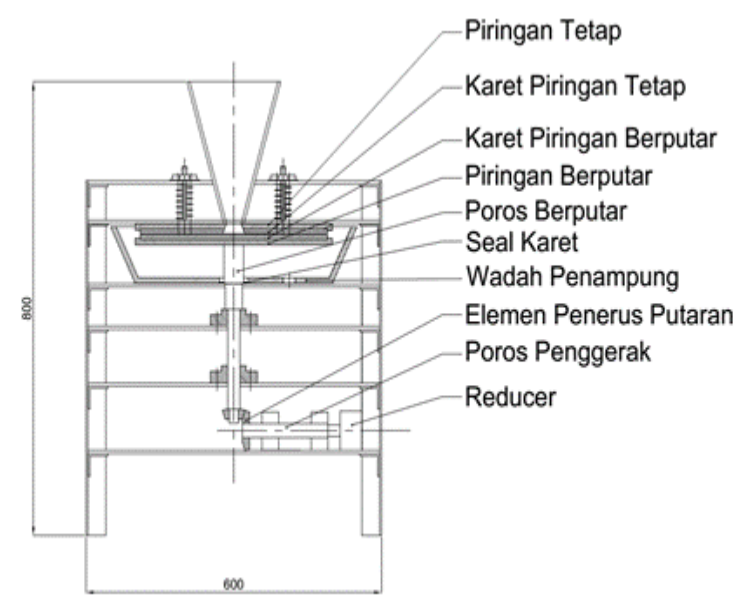

\section{Gambar 3 Rakitan Alat Pengupas Lada dengan Sistem Crusher [1]}

Kemiringan piringan lada mempengaruhi persentase hasil lada terkelupas dan kapasitas output mesin. [1] Menggunakan kemiringan piringan sebesar $0,68^{\circ}$ didapatkan persentase lada terkelupas sebesar 70\% dengan kapasitas output sebesar 0,64 $\mathrm{kg} / \mathrm{jam}$. [2] Dengan kemiringan piringan sebesar $0,53^{\circ}$ didapatkan persentase lada terkelupas sebesar $50 \%$ denngan kapasitas output mesin sebesar 0,52 $\mathrm{kg} / \mathrm{jam}$. Dari hasil penelitian didapatkan kemiringan jarak piringan yang optimum didapatkan sebesar $0,68^{\circ}$ dengan bentuk kemiringan dapat dilihat pada gambar 4.

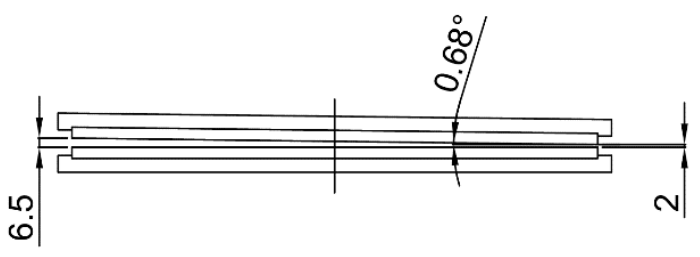

Gambar 4 Kemiringan Piringan [1]

Berdasarkan hasil penelitian terdahulu, diameter inlet sebesar $30 \mathrm{~mm}$ didapatkan kapasitas input $1 \mathrm{~kg} / \mathrm{jam}$, kapasitas output 0,64 kg/jam dengan berat sample sebanyak 100 gram. Waktu yang diperlukan untuk proses pengelupasan 100 gram lada didapatkan waktu proses rata-rata selama 6 menit. Lamanya waktu proses dipengaruhi oleh diameter inlet yang terlalu sempit sehingga menyebabkan rendahnya kapasitas input mesin.

Kekerasan karet pun dapat mempengaruhi hasil pengelupasan lada. [3] Bahan karet dari alam dapat diperkuat dengan benang-benang sehingga cukup kuat dan elastis sehingga mempengaruhi gesekan dan penekanan pada lada. [4] kekerasan karet merupakan sifat yang sangat mempengaruhi penampilan dan ketahanan barang jadi karet sehingga perlu dilakukan penelitian hubungan antara kekerasan karet dengan hasil pengelupasan lada.

\section{METODOLOGI PENELITIAN}

Penelitian ini dilakukan dengan mengumpulkan data hasil penelitian terdahulu. Secara umum, alur penelitian sebagai berikut:

1. Pengumpulan data, pengumpulan data dilakukan dengan mengumpulkan data primer mesin pengupasan lada penelitian terdahulu

2. Evaluasi penelitiaan terdahulu dan memodifikasi diameter inlet mesin terdahulu dan kemudian menganalisa berdasarkan kapasitas input mesin.

3. Memvariasikan karet pada piringan berputar dengan kekerasan 60 shore A dan 70 shore A.

Pengolahan data yang dilakukan berdasarkan hasil uji coba tiga sampel dengan berat sampel 250 gram pada masing-masing kekerasan 60 dan 70 shore A. Waktu proses dihitung mulai lada 
dimasukkan ke inlet sampai dengan lada tidak tersisa di inlet. Analisa yang dilakukan terdiri dari:

1. Mengukur waktu proses pengelupasan lada

2. Berat lada yang terkelupas, dengan spesifikasi tidak ada kulit lada yang menempel pada lada

3. Berat kulit lada yang tertinggal, dengan spesifikasi perhitungan berat kulit lada tanpa adanya bij lada

4. Berat lada tidak terkelupas, dengan spesifikasi lada yang masih utuh terbungkus kulit lada maupun lada yang tidak utuh terbungkus kulit lada.

5. Menghitung persentase kehilangan lada akibat terbawa air (loses) dengan perhitungan : loses $=\frac{N-N 1+N 2+N 3}{N} \times 100 \%$

6. Perhitungan persentase lada terkelupas dengan meggunakan rumus:

$\%=\frac{N 1+N 2}{N 1+N 2+N 3} \times 100 \%$

Dimana:

$\mathrm{N}=$ berat lada yang masuk

$\mathrm{N} 1=$ berat lada terkelupas

$\mathrm{N} 2=$ berat kulit lada yang terkelupas

N3=berat lada yang tidak terkelupas

7. Memvisualisasikan hasil lada yang dikeringkan dengan waktu kering yang sama

8. Membandingkan hasil lada dengan variasi kekerasan karet.

\section{HASIL DAN PEMBAHASAN}

\section{Data Awal Penelitian Terdahulu}

Dari data penelitian sebelumnya didapatkan data sebagai berikut:

- Dimensi mesin pengupas lada dengan sistem crusher $600 \times 600 \times 800 \mathrm{~mm}$

- Daya motor yang digunakan sebesar $1 \mathrm{~kW}$ dengan putaran motor sebesar $1400 \mathrm{rpm}$ dan menggunakan reducer 1:60.

- Elemen penerus putaran menggunakan bevel gear dengan kecepatan putar pada piringan berputar sebesar $15 \mathrm{rpm}$

- Diameter inlet untuk memasukkan lada sebesar $30 \mathrm{~mm}$ dan diameter piringan sebesar $400 \mathrm{~mm}$ dan dengan kemiringan piringan sebesar $0,68^{\circ}$.

- Permukaan karet berputar mempunyai alur-alur dengan lebar $1 \mathrm{~mm}$ dan kedalaman $1 \mathrm{~mm}$.

\section{Evaluasi dan Modifikasi Diameter Inlet}

Rendahnya kapasitas input mesin disebabkan karena terlalu sempitnya diameter inlet. Untuk itu perlu memodifikasi diameter inlet dengan memperbesar diameter inlet $30 \mathrm{~mm}$ menjadi $50 \mathrm{~mm}$.

Dari hasil memperbesar diameter didapatkan data seperti pada tabel 1 .
Tabel 1 Perbandingan Waktu Proses Penelitian Terdahulu Berdasarkan Modifikasi Diameter

Inlet

\begin{tabular}{|c|c|c|c|c|}
\hline \multirow[b]{2}{*}{ Sampel } & \multicolumn{2}{|c|}{$\begin{array}{c}\text { Kekerasan Karet } \\
60 \text { Shore A }\end{array}$} & \multicolumn{2}{|c|}{$\begin{array}{c}\text { Kekerasan } 70 \\
\text { Shore A }\end{array}$} \\
\hline & $\begin{array}{c}\text { Berat } \\
\text { Awal } \\
\text { (gram) }\end{array}$ & $\begin{array}{r}\text { Waktu } \\
\text { (menit) }\end{array}$ & $\begin{array}{c}\text { Berat } \\
\text { Awal } \\
\text { (gram) }\end{array}$ & $\begin{array}{r}\text { Waktu } \\
\text { (menit) }\end{array}$ \\
\hline 1 & 100 & 5,04 & 250 & 2,50 \\
\hline 2 & 100 & 6,51 & 250 & 2,50 \\
\hline 3 & 100 & 6,45 & 250 & 2,50 \\
\hline Rata-rata & 100 & 6,00 & 250 & 2,50 \\
\hline
\end{tabular}

Dari hasil uji coba dengan menggunakan mesin pengupas lada dapat dianalisa bahwa semakin besar diameter inlet maka semakin banyak jumlah lada yang masuk ke dalam piringan berputar sehingga akan meningkatkan waktu proses. Dari penelitian terdahulu didapatkan rata-rata waktu proses sebesar 6 menit untuk input lada sebesar 100 gram. Dengan memodifikasi diameter inlet, waktu proses dapat di percepat menjadi 2 menit 30 detik untuk input lada sebesar 250 gram. Dari tabel 1 didapatkan bahwa kapasitas input hasil penelitian terdahulu sebesar 1 $\mathrm{kg} / \mathrm{jam}$ dan kapasitas input hasil penelitian modifikasi diameter inlet sebesar 100 gram/menit atau $6 \mathrm{~kg} / \mathrm{jam}$. Dengan memodifikasi diameter inlet, maka terjadi kenaikan kapasitas input sebesar 5 kalinya dibandingkan dengan penelitian terdahulu. Ini menandakan bahwa diameter inlet mempengaruhi kapasitas input mesin. Semakin besar diameter inlet maka kapasitas input semakin besar. Namun pembesaran diameter inlet perlu disesuaikan dengan diameter piringan tetap yang mempunyai diameter sebesar $400 \mathrm{~mm}$.

\section{Variasi Kekerasan Karet}

Uji coba dilakukan dengan menggunakan kecepatan putar pada piringan putar sebesar $15 \mathrm{rpm}$, kekerasan karet pada piringan tetap sebesar 85 shore A dan variasi kekerasan karet pada piringan putar sebesar 60 shore A dan 70 shore A.

- Kekerasan karet 60 shore A

Dengan menggunakan karet pada piringan berputar sebesar 60 shore A didapatkan data seperti pada tabel 2 .

Tabel 2 Hasil Pengelupasan Lada dengan Kekerasan Karet 60 Shore A

\begin{tabular}{|c|c|c|c|c|c|}
\hline \multirow{2}{*}{ Sample } & \multirow{2}{*}{$\begin{array}{c}\text { Berat } \\
\text { Kulit } \\
\text { (gram) }\end{array}$} & \multicolumn{2}{|c|}{$\begin{array}{c}\text { Lada } \\
\text { Terkelupas }\end{array}$} & \multicolumn{2}{|c|}{$\begin{array}{l}\text { Lada Tidak } \\
\text { Terkelupas }\end{array}$} \\
\hline & & $\begin{array}{l}\text { Berat } \\
\text { (gram) }\end{array}$ & $\%$ & $\begin{array}{c}\text { Berat } \\
\text { (gram) }\end{array}$ & $\%$ \\
\hline Samp & 91 & 93 & 37,20 & 65 & 26,00 \\
\hline ample 2 & 88 & 92 & 36,80 & 70 & 28,00 \\
\hline Samp & 90 & 93 & 37,20 & 67 & 26,80 \\
\hline Rata-rata & 89,67 & 92,67 & 37,07 & 67,33 & 26,93 \\
\hline
\end{tabular}


Dari hasil pengujian didapatkan bahwa persentase lada terkelupas sebesar $72,13 \%$, lada yang tidak terkelupas sebesar $27,87 \%$ dan loses yang terjadi sebesar $0 \%$ dengan kapasitas output mesin sebesar 4,33 kg/jam. Untuk hasil lada yang dikeringkan dapat dilihat pada gambar 5 .

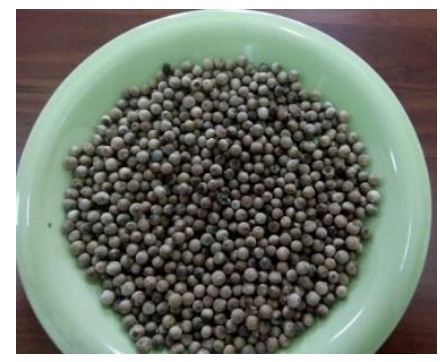

Gambar 5 Lada Kering dengan Kekerasan Karet 60 Shore A

- Kekerasan karet 70 shore A

Dengan menggunakan karet pada piringan berputar sebesar 70 shore A didapatkan data seperti pada tabel 3 .

Tabel 3 Hasil Pengelupasan Lada dengan Kekerasan Karet 70 Shore A

\begin{tabular}{|c|c|c|c|c|c|}
\hline \multirow{2}{*}{ Sample } & \multirow{2}{*}{$\begin{array}{c}\text { Berat } \\
\text { Kulit } \\
\text { (gram) }\end{array}$} & \multicolumn{2}{|c|}{$\begin{array}{c}\text { Lada } \\
\text { Terkelupas } \\
\end{array}$} & \multicolumn{2}{|c|}{$\begin{array}{c}\text { Lada Tidak } \\
\text { Terkelupas }\end{array}$} \\
\hline & & $\begin{array}{l}\text { Berat } \\
\text { (gram) }\end{array}$ & $\%$ & $\begin{array}{c}\text { Berat } \\
\text { (gram) }\end{array}$ & $\%$ \\
\hline Sample 1 & 91 & 93 & 37,20 & 65 & 26,00 \\
\hline Sample 2 & 88 & 92 & 36,80 & 70 & 28,00 \\
\hline Sample 3 & 90 & 93 & 37,20 & 67 & 26,80 \\
\hline Rata-rata & 89,67 & 92,67 & 37,07 & 67,33 & 26,93 \\
\hline
\end{tabular}

Dari hasil pengujian didapatkan bahwa persentase lada terkelupas sebesar 73,03\%, lada yang tidak terkelupas sebesar $26,93 \%$ dan loses yang terjadi sebesar $0,04 \%$ dengan kapasitas output mesin sebesar 4,38 kg/jam. Untuk hasil lada yang dikeringkan dapat dilihat pada gambar 6.

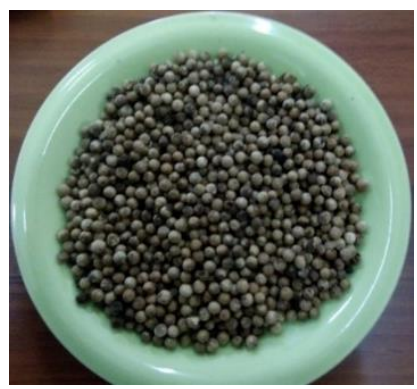

Gambar 6 Lada Kering dengan Kekerasan Karet 70 Shore A
Dari perbandingan 2 variasi kekerasan karet, didapatkan data yang terlihat pada gambar 7 .

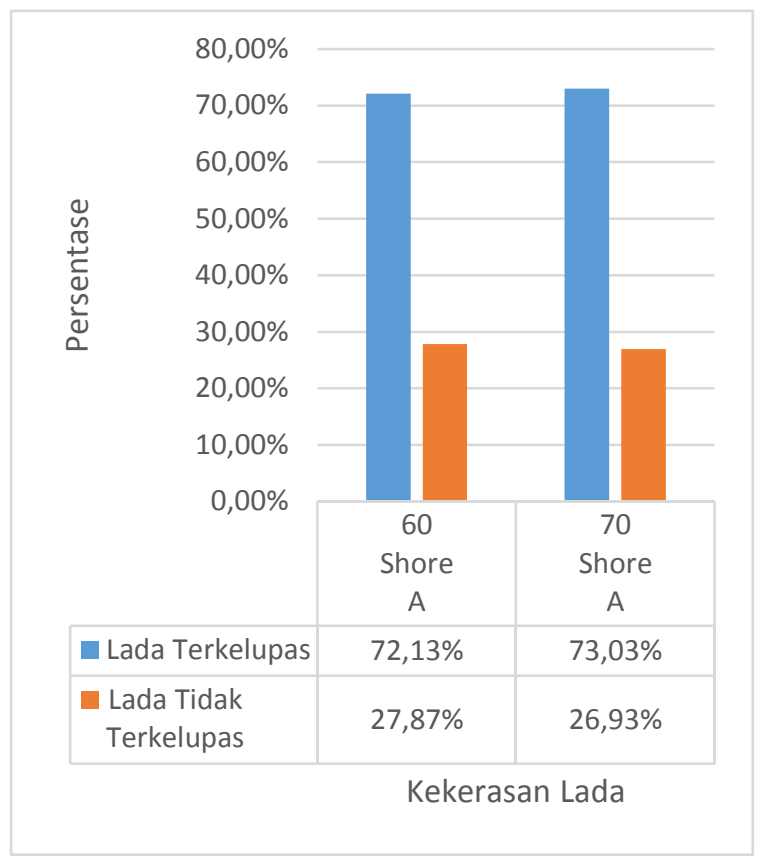

\section{Gambar 7 Perbandingan Persentase Lada Terkelupas}

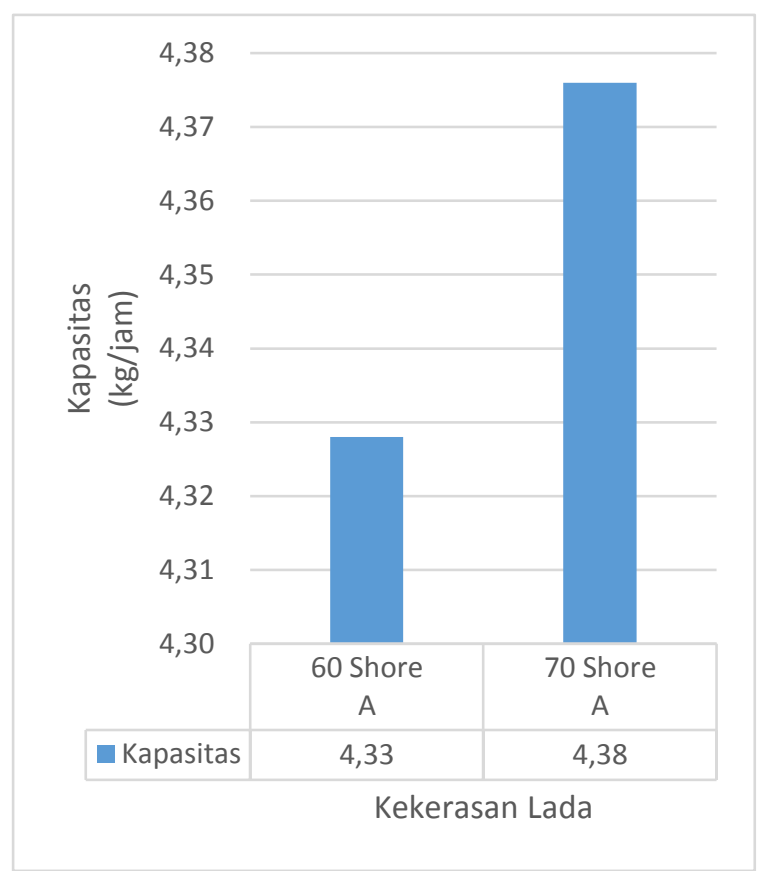

Gambar 8 Perbandingan Kapasitas Output Mesin 
Dari gambar 7 dapat dinyatakan bahwa semakin keras karet maka persentase lada yang terkelupas semakin besar. Begitu juga jika ditinjau dari kapasitas output mesin, semakin keras karet kapasitas output mesin semakin tinggi. Namun ditinjau dari hasil lada yang dikeringkan, semakin keras lada, hasil lada kering semakin gelap.

\section{UCAPAN TERIMAKASIH}

Terima kasih kepada Universitas Bangka Belitung yang telah memberikan konstribusi dalam pendanaan penelitian ini dalam Program Penelitian Dosen Tingkat Jurusan dengan skema pendanaan tahun 2018.

\section{KESIMPULAN}

1. Perubahan dimensi inlet mempengaruhi kapasitas input mesin. Semakin besar diameter inlet maka kapasitas input mesin semakin tinggi.

2. Kekerasan karet mempengaruhi hasil pengelupasan lada. Semakin keras karet, persentase lada terkelupas dan kapasitas output mesin semakin meningkat, namun warna lada yang dikeringkan akan semakin gelap.

\section{DAFTAR PUSTAKA}

[1] F. Rosa, Rodiawan, and Saparin, "RANCANG BANGUN PENGUPAS BIJI LADA MENGGUNAKAN SISTEM CRUSHER," J. Ipteks Terap., vol. 12, no. 2, pp. 177-183, 2018.

[2] F. Rosa, Rodiawan, and Saparin, "ANALISA HASIL UJI COBA MESIN PENGUPAS BIJI LADA MENGGUNAKAN SISTEM CRUSHER DENGAN VARIASI KEMIRINGAN PIRINGAN SEBESAR 0,53 INFORMASI ARTIKEL ABSTRAK," Fly Wheel, vol. IV, no. 1, pp. 1-4, 2018.

[3] C. F. Zuhra, "Cut Fatimah Zuhra, SSi. MSi.," USU Repos., pp. 1-30, 2006.

[4] F. Delvitasari, "KARAKTERISTIK SIFAT FISIKA KOMPON KARET ALAM SEBAGAI BAHAN DASAR FOOTSTEP SEPEDA MOTOR DENGAN BERBAGAI FORMUlA," J. Din. Penelit. Ind., vol. 29, no. 1 , pp. 29-34, 2018. 